\title{
Breast milk odor via olfactometer for tube-fed, premature infants
}

\author{
Peter M. Bingham, David Churchill, and Taka Ashikaga \\ University of Vermont, Burlington, Vermont
}

\begin{abstract}
Human newborns use odor cues to orient to their source of nutrition. However, tube-fed, premature infants have restricted chemosensory experience. New methods of introducing breast milk odor to tube-fed premature infants will permit empiric tests of the effect of controlled exposure to nutrient odor. We therefore developed an infant olfactometer and piloted its use in 7 tube-fed, premature infants in the neonatal intensive care unit. Since nonnutritive sucking shortens the amount of time required to wean from tube-feeding, we tested the effect of breast milk odor on nonnutritive sucking. Six out of 7 subjects responded to breast milk odor with an increase in number of sucks. Statistical analysis supported the hypothesis that breast milk odor reinforces nonnutritive sucking. These results indicate the feasibility and potential of this experimental approach, and warrant further study of the effect of controlled nutrient odor exposure on feeding behavior of premature infants.
\end{abstract}

Mammalian newborns, including human newborns, use olfactory cues for social recognition as well as to orient to their source of energy (i.e., breast milk) (Doty, 1986; Leon, 1983; Porter \& Schaal, 1995; Varendi, Porter, \& Winberg, 1994). Odor stimuli activate ingestive behavior such as rooting and nonnutritive sucking (Makin \& Porter, 1989; Porter, 1991). However, tube-fed, premature infants have restricted chemosensory experience of their mothers. The degree to which disrupted olfactory communication between newborns and their mothers contributes to feeding difficulty or interferes with mother-infant bonding in this high risk population is unknown. An answer to this question will depend upon the development of methods of re-introducing breast milk odor to tube-fed premature infants so that positive effects of controlled exposure to maternal nutrient odor can be measured.

Studies by experimental psychologists support the contention that infants can perceive and respond to odors from a very early age. The human fetus, like other mammals (Smotherman, 1982), forms learned responses depending upon exposure to odorants in amniotic fluid (Mennella, Jagnow, \& Beauchamp, 2001). Infants respond to odors with changes in facial expression (Soussignan, Schaal, Marlier, \& Jiang, 1997), nonnutritive sucking (NNS) activity (Marlier, Schaal, \& Soussignan, 1998), respiratory pattern (Soussignan et al., 1997), and cerebral blood flow (Bartocci et al., 2001).

In the setting of prematurity, the stimulation of NNS (sucking movements in the absence of swallowing/feeding) holds particular interest, because this activity improves feeding skills and shortens hospital stay for these patients (Bernbaum, Periera, Watkins, \& Peckham, 1983; Field et al., 1982; Measel \& Anderson, 1979; Pinelli \&
Symington, 2005). These favorable effects suggest that further efforts to reinforce and enhance NNS may augment clinical benefits. We therefore investigated the effect of nutrient odor (breast milk odor) delivered via olfactometer on NNS in tube-fed, premature infants.

\section{Method}

In an earlier study on odor-induced feeding behavior by pre-term infants, we modified a silicone pacifier (Soothie pacifier, Hawaii Medical, Boston) used in many neonatal intensive care units (NICUs), so that it would release an odor contingent upon NNS by the infants (Osmophore pacifier, see Figure 1) (Bingham, Abbasi, \& Sivieri, 2003). To deliver nutrient or maternally derived odors to infants in a controlled and repeatable manner, we constructed an infant olfactometer (Figure 2).

Flow rate, temperature, and humidity characteristics of the olfactometer are similar to those for delivering supplementary oxygen to pre-term infants. The device separates airflow from the medical grade hospital air supply into a control airstream and an experimental airstream. Each airstream is regulated to $0.5 \mathrm{~L} / \mathrm{min}$. The two experimental airstreams are directed via three-way valves to flow either through their respective air circuits (experimental odor), or to an exhaust port (no air delivered). The airstream passes through humidification, test odor, and vapor trap chambers, and is conveyed to the subject via a standard infant nasal cannula mounted on a pacifier. Activating flow through the test odor circuit delivers test odor to the subject without changing the net flow of humidified air to the subject. Activating the control circuit delivers a nonodorized air to the subject. Algorithms programmed in Labview (National Instruments, Austin, TX) permit

P. M. Bingham, peter.bingham@vtmednet.org 
A

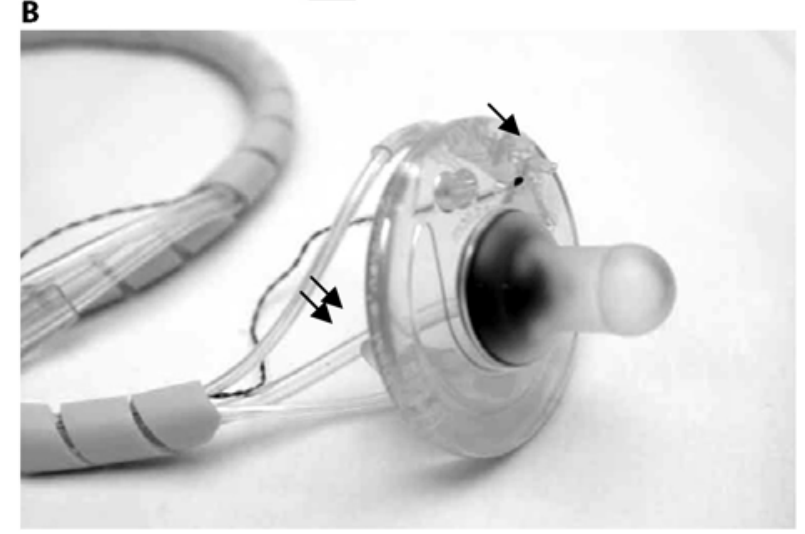

Figure 1. (A) Schematic side view of an osmophore (odorreleasing) pacifier (U.S. Patent No. 6,482,225). Infant sucking increases convection of odorous air through a gauze saturated with odorant solution (breast milk) and also through cannulae mounted on the pacifier hilt. (B) A Soothie pacifier is connected to both an infant nasal cannula mounted on the nipple shield (arrow) and also to a pressure transducer (via tubing; double arrow)

control of olfactometer switches so as to deliver odor according to a fixed schedule (noncontingent exposure), or in response to infant sucking (contingent exposure). The noncontingent exposure occurs as a 10 -sec pulse every $30 \mathrm{sec}$, while the contingent exposure is delivered only after $5 \mathrm{sec}$ of continuous sucking activity, and then lasts $5 \mathrm{sec}$ (see Figures 3A and 3B). All parts of the system are coupled with tubing, stopcocks, and valves that are in standard use in clinical care.

The odor-releasing pacifier also functions as a component of a suckometer as follows: a tube is placed through a plunger at the back of the pacifier so as to connect the luminal airspace within the pacifier to a pressure transducer. Positive intraluminal pressure associated with sucking produces a signal that can be visualized on the $\mathrm{PC}$ and stored for later blinded assessment of NNS. A similar device was described by Hafström, Lundquist, Lindecrantz, Larsson, and Kjellmer (1997), except that these researchers employed a software algorithm that continually compares sucking deflections to background in order to avoid false positive identification of infant sucking activity. The signal-to-noise ratio in our system obviated the necessity of such an algorithm. Suck bursts are defined as a sequence of two or more sucks whose peaks are no more than $1 \mathrm{sec}$ apart. Software algorithms programmed in Labview software extract the number of sucks, bursts, sucks per burst, and other measures. Preliminary data using this suckometer program show that the automated computer algorithm reliably measures the number of bursts and sucks compared to a visual assessment of sucks on videotape.

The olfactometer was first tested on 10 adult subjects, who wore a standard nasal cannula for at least $30 \mathrm{~min}$ with a flow rate of $2 \mathrm{~L} / \mathrm{min}$. These subjects reported no irritation or mucosal drying during these trials; when tested with lemon tea versus water, subjects consistently made correct odor discriminations. Using a protocol described in more detail below, we then tested 6 full-term newborn subjects with the olfactometer/suckometer. Subjects were exposed to formula odor using a contingent exposure condition. These trials indicated that the device performed reliably and that infant subjects tolerated exposure to the controlled airflow when the cannulae were mounted on a standard pacifier.

In a within-subjects, controlled trial, nonnutritive sucking responses of 7 premature infants who were consuming pumped breast milk were tested in $4-12$ observations (see Table 1). These infants were breathing comfortably in room air, and were concurrently receiving tube feed-

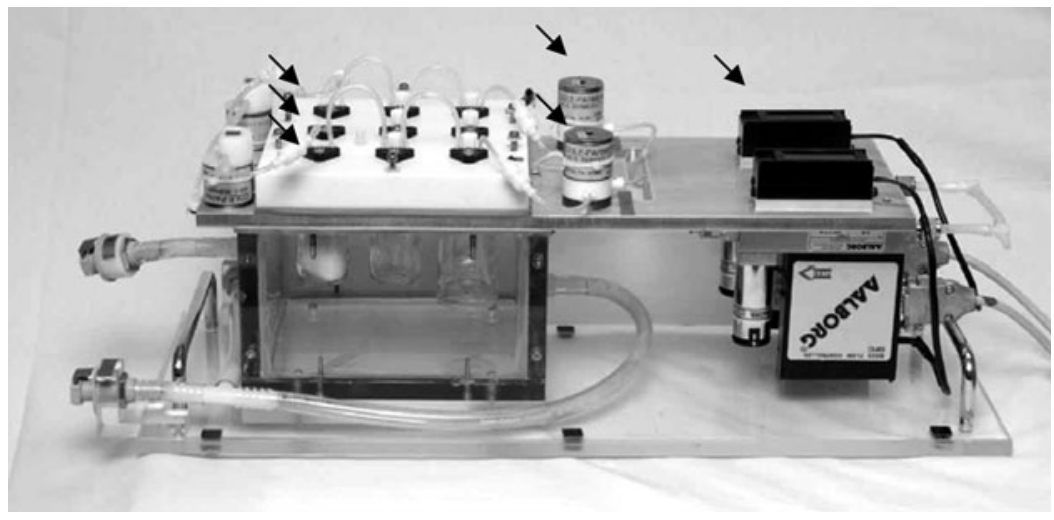

Figure 2. Infant olfactometer. Air flow through parallel circuits (arrows at left) is regulated by clamp switches (middle arrows) and mass flow controllers (arrow at right). 

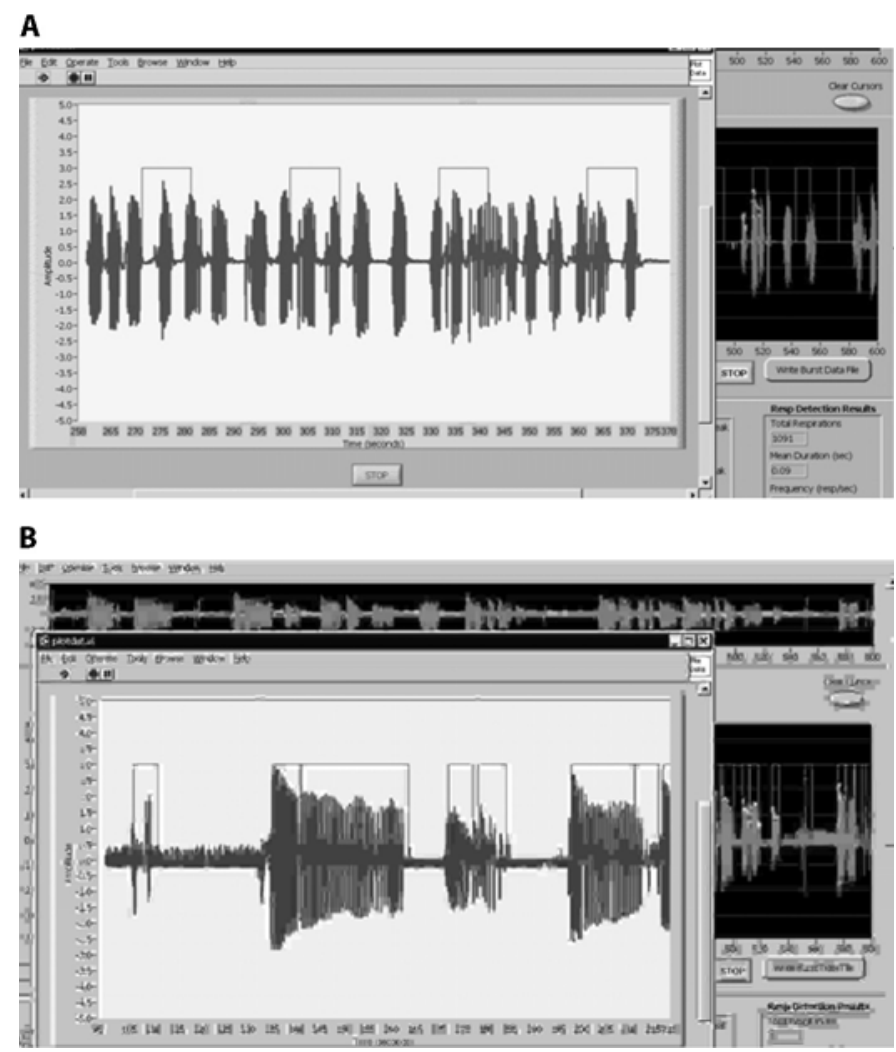

Figure 3. (A) The tracing shows the regular burst pattern of organized infant sucking behavior. The lighter gray brackets show timing of periodic, 5-sec odor exposure via olfactometer. (B) Odor exposure could be made contingent upon infant sucking bursts.

ing via nasogastric tube at the time of the observations. Each observation lasted $10 \mathrm{~min}$, and was conducted in association with a single tube-feeding, so that observations were conducted at least $3 \mathrm{~h}$ apart for each subject. Since premature infants show increasing sucking activity as they mature (Hafström \& Kjellmer, 2000), we were careful to ensure that the trials were conducted within a 3-day span, so that maturation would not confound suck measures. The sequence of trials (odor vs. nonodor) was counterbalanced so that a similar number of subjects underwent the first trial with versus without odor exposure.

For statistical analysis, only noncontingent trials were analyzed because there were adequate data for 6 of the 7 subjects to compare results from 2-4 observations with odor versus without odor exposure. The average number of sucks during "odor" versus "no-odor" trials was calculated and then compared using a nonparametric statistical test for the paired data (the Wilcoxon signed rank test).

\section{Results}

Figures $3 \mathrm{~A}$ and $3 \mathrm{~B}$ illustrate the delivery of odor stimuli contingent upon NNS or on a fixed schedule. Each of the six subjects with adequate data showed a greater mean number of sucks with breast milk odor exposure compared to the no-odor condition (see summary, Table 2). There was an inadequate number of trials for comparison under the contingent odor condition. However, the signed rank test indicated a significant difference between odor and no-odor conditions (two-tailed, $p=.05$ ). Thus, the median number of sucks was larger under the odor con-

Table 1

Characteristics of 6 Premature Infants Tested With the Infant Olfactometer

\begin{tabular}{cccccc}
\hline $\begin{array}{c}\text { Subject } \\
\text { Number }\end{array}$ & $\begin{array}{c}\text { Birth } \\
\text { Weight }(\mathrm{g})\end{array}$ & $\begin{array}{c}\text { Age at Test } \\
\text { (days) }\end{array}$ & $\begin{array}{c}\text { Weeks Postconceptional } \\
\text { Age at Test }\end{array}$ & $\begin{array}{c}\text { Sex } \\
\text { Volume (mL) }\end{array}$ & $\begin{array}{c}\text { Tube Feed } \\
\text { Volume }\end{array}$ \\
\hline 1 & 1,543 & 10 & $33+2$ days & $\mathrm{M}$ & 28 \\
2 & 1,899 & 10 & $33+5$ days & $\mathrm{F}$ & 38 \\
3 & 2,054 & 17 & $34+5$ days & $\mathrm{F}$ & 41 \\
4 & 1,838 & 10 & $34+5$ days & $\mathrm{M}$ & 35 \\
5 & 2,353 & 10 & $33+5$ days & $\mathrm{M}$ & 46 \\
6 & 1,210 & 16 & 36 & $\mathrm{~F}$ & 25 \\
\hline
\end{tabular}

Note-Tube feed volume is volume delivered at the time of the sucking observations. 
Table 2

Measures of Sucking and Sucking Bursts in 6 Subjects in Whom More Than Two Observations With Odor (Noncontingent Exposure) and More Than Two Observations Without Odor Exposure (Noncontingent Odor Condition) Were Available

\begin{tabular}{lcccc}
\hline & $\begin{array}{c}\text { Sucks } \\
\text { (No Odor) }\end{array}$ & $\begin{array}{c}\text { Sucks } \\
\text { (Odor) }\end{array}$ & $\begin{array}{c}\text { Bursts } \\
\text { (No Odor) }\end{array}$ & $\begin{array}{c}\text { Bursts } \\
\text { (Odor) }\end{array}$ \\
\hline Minimum & 84.0 & 134.0 & 20.0 & 27.0 \\
Maximum & 391.0 & 434.0 & 61.0 & 60.0 \\
Range & 307.0 & 300.0 & 41.0 & 33.0 \\
Median & 238.5 & 282.0 & 37.5 & 44.5 \\
Mean & $250.2^{*}$ & $286.8^{*}$ & 40.3 & 44.7 \\
95\% CI Upper & 365.9 & 388.5 & 57.7 & 59.3 \\
95\% CI Lower & 134.5 & 185.1 & 23.0 & 30.1 \\
\hline
\end{tabular}

*two-tailed, $p=.05$.

dition compared to the no-odor condition using the noncontingent exposure condition. The signed rank statistical analysis for number of suck bursts showed no significant difference between odor and no-odor conditions (onetailed, $.20<p<.30$ ).

\section{Discussion}

We describe a feasible means of delivering nutrient (breast milk) odor to tube-fed premature infants using an infant olfactometer linked to a standard infant pacifier. Premature infant subjects responded to this exposure with increased nonnutritive sucking. The performance attributes of this infant olfactometer include (1) it is selfcontained and able to be used in a cramped, clinical space; (2) it delivers humidified air at a consistent flow volume and temperature, with no signs of irritation in study subjects; (3) the device can be programmed to deliver odor noncontingently or contingent upon a specific target behavior (nonnutritive sucking) by the infant.

The reasons why maternally derived odors make good candidates as olfactory reinforcers of neonatal ingestive behavior are fundamental to the feeding ecology of newborns (Makin \& Porter, 1989; Porter, 1991; Varendi, Porter, \& Winberg, 1994). Evidence suggests that olfactory properties of breast milk overlap those of amniotic fluid, and that the positive or reinforcing qualities of amniotic fluid odor for newborns is soon superceded by those of breast milk (Varendi, Porter, \& Winberg, 1997). The chemosensory properties of both amniotic fluid and breast milk depend on maternal diet (Mennella \& Beauchamp, 1991; Mennella, Johnson, \& Beauchamp, 1995). According to an emerging model of olfactory learning and feeding ecology among mammals, iterative exposure to odorants derived from maternal diet serve to influence dietary preferences of the infant, so that they in effect receive a dietary preference "education" via odorants in their primary, maternally derived, source of nutrition (Galef \& Henderson, 1972; Mennella, Jagnow, \& Beauchamp, 2001).

Limitations of this study include a small sample size. Subjects were fairly close in their equivalent gestational age at the time of testing ( 33 weeks +2 days -36 weeks; see Table 1). Differences in gestational age should not confound results in this within-subjects design (Hafström \& Kjellmer, 2000). Future studies involving a larger number of subjects will be necessary to confirm whether sys- tematic delivery of olfactory stimuli via olfactometer induces NNS. While evidence supports an effect of prenatal odor exposure on later dietary preferences in humans, the influence of early, postnatal exposure to odorants on later feeding patterns has not yet been investigated.

In summary, these results indicate the feasibility and potential of this experimental approach, showing that the infant olfactometer may be used to rigorously assess the effect of controlled odor exposure on infant behavior in the setting of the neonatal intensive care unit. Nutrient odor may increase nonnutritive sucking by premature infants (Bingham, Abbasi, \& Sivieri, 2003). Considering the substantial clinical benefits that have been associated with this ingestive behavior in tube-fed premature infants, controlled nutrient odor exposure as a developmental intervention warrants further study in high risk newborns. An ultimate objective of this intervention will be to improve breastfeeding by premature infants, whose breastfeeding is frequently interrupted within 2 or 3 months of birth (Furman, Minich, \& Hack, 1998; Hall, 2001).

\section{AUTHOR NOTE}

This study was supported by Grant R01 NR010166 from the National Institute for Nursing Research, by a grant from the Fletcher Allen Health Care Research Development Foundation, and by the Department of Neurology, Fletcher Allen Health Care. The authors gratefully acknowledge the families of infants who participated in this study. Gary Wysocki and Paul Wise provided advice on the design of the infant olfactometer, and James Fox provided Labview programming expertise. We thank Doug Gomez and the University of Vermont's Instrument and Modeling Facility for help with construction of the olfactometer. We thank Debbie Stevens-Tuttle and nurses of the Neonatal Intensive Care Unit at Fletcher Allen Health Care for carrying out NICU observations. The first author holds a patent for a device (osmophore pacifier) described in this article. Correspondence concerning this article should be addressed to P. M. Bingham, Fletcher Allen Health Care, University of Vermont, One South Prospect St., Burlington, VT 05401 (e-mail: peter.bingham@vtmednet .org).

\section{REFERENCES}

Bartocci, M., Winberg, J., Papendieck, G., Mustica, T., Serra, G., \& Lagercrantz, H. (2001). Cerebral hemodynamic response to unpleasant odors in the preterm newborn measured by near-infrared spectroscopy. Pediatric Research, 50, 324-330.

Bernbaum, J. C., Periera, G. R., Watkins, J. B., \& Peckham, G. J. (1983). Nonnutritive sucking during gavage feeding enhances growth and maturation in premature infants. Pediatrics, 71, 41-45.

Bingham, P. M., Abbasi, S., \& Sivieri, E. (2003). A pilot study of milk odor effect on non-nutritive sucking by premature infants. Archives of Pediatrics \& Adolescent Medicine, 157, 72-75.

Doty, R. (1986). Odor guided behavior in mammals. Experientia, 42, 257-271.

Field, T., Ignatoff, E., Stringer, S., Brennan, J., Greenberg, R., Widmayer, S., \& Anderson, G. C. (1982). Nonnutritive sucking during tube feedings: Effects on preterm neonates in an intensive care unit. Pediatrics, 70, 381-384.

Furman, L., Minich, N. M., \& HaCK, M. (1998). Breastfeeding of very low birth weight infants. Journal of Human Lactation, 14, 29-34.

Galef, B. G., \& Henderson, P. W. (1972). Mother's milk: A determinant of the feeding preferences of weaning rat pups. Journal of Comparative \& Physiological Psychology, 78, 213-219.

Hafström, M., Lundquist, C., Lindecrantz, K., Larsson, K., \& KJELLMER, I. (1997). Recording non-nutritive sucking in the neonate. Description of an automatized system for analysis. Acta Paediatrica, 86, 82-90.

Hafström, M., \& KJellmer, I. (2000). Non-nutritive sucking in the healthy pre-term infant. Early Human Development, 60, 13-24. 
HALL, R. T. (2001). Nutritional follow-up of the breastfeeding premature infant after hospital discharge. Pediatric Clinics of North America, 48, 453-460.

LEON, M. (1983). Chemical communication in mother-young interactions. In J. G. Vandenbergh (Ed.), Pheromones and reproduction in mammals (pp. 39-77). New York: Academic Press.

MaKin, J. W., \& Porter, R. H. (1989). Attractiveness of lactating females' breast odors to neonates. Child Development, 60, 803-810.

Marlier, L., SchaAl, B., \& Soussignan, R. (1998). Neonatal responsiveness to the odour of amniotic fluid and lacteal fluids: A test of perinatal chemosensory continuity. Child Development, 69, 611-623.

Measel, C., \& Anderson, G. (1979). Nonnutritive sucking as a clinical assessment tool: Preliminary findings. Journal of Obstetric \& Gynecologic Neonatal Nursing, 8, 265.

Mennella, J. A., \& Beauchamp, G. K. (1991). Maternal diet alters the sensory qualities of human milk and the nursling's behavior. Pediatrics, 88, 737-744.

Mennella, J. A., Jagnow, C. P., \& Beauchamp, G. K. (2001). Prenatal and postnatal flavor learning by human infants. Pediatrics, 107, e88.

Mennella, J. A., Johnson, A., \& Beauchamp, G. K. (1995). Garlic ingestion by pregnant women alters the odor of amniotic fluid. Chemical Senses, 20, 207-209.

Pinelli, J., \& Symington, A. (2005). Non-nutritive sucking for promot- ing physiologic stability and nutrition in preterm infants. Cochrane Database of Systematic Reviews, Issue 4. Art. No.: CD001071. DOI: 10.1002/14651858.CD001071.pub2.

PORTER, R. (1991). An assessment of the salient olfactory environment of formula-fed infants. Physiology \& Behavior, 50, 907.

Porter, R., \& SchaAL, B. (1995). Olfaction and development of social preferences in neonatal organisms. In R. Doty (Ed.), Handbook of olfaction and gustation (pp. 299-321). New York: Dekker.

Smotherman, W. (1982). In utero chemosensory experience alters taste preferences and corticosterone responsiveness. Behavioral \& Neural Biology, 36, 61-68.

Soussignan, R., Schaal, B., Marlier, L., \& Jiang, T. (1997). Facial and autonomic responses to biological and artifical olfactory stimuli in human neonates: Re-examining early hedonic discrimination of odors. Physiology \& Behavior, 62, 745-758.

Varendi, H., Porter, R. H., \& Winberg J. (1994). Does the newborn baby find the nipple by smell? Lancet, 344, 989-990.

VARENDi, H., Porter, R. H., \& Winberg J. (1997). Natural odour preferences of newborn infants change over time. Acta Paediatrica, 86, 985-990.

(Manuscript received March 30, 2006; revision accepted for publication August 17, 2006.) 